\title{
Autologous bone marrow stem cell implantation in treatment of thromboangiitis obliterans
}

\author{
Ali İhsan Tekin ${ }^{1}$, Mehmet Erdem Memetoğlu ${ }^{2}$, Rasim Kutlu ${ }^{3 *}$ Ümit Arslan ${ }^{4}$, Osman Nuri Tuncer $^{5}$, Bayram Yağmur $^{1}$, Cengiz Türkay $^{5}$ and \\ Mehmet Coşkun ${ }^{2}$ \\ ${ }^{1}$ Kayseri Educating and Training Hospital, Department of Cardiovascular Surgery, Kayseri, Turkey \\ ${ }^{2}$ Dr. Siyami Ersek Cardiovascular and Thoracic Surgery Hospital, Department of Cardiovascular Surgery, İstanbul, Turkey \\ ${ }^{3}$ Giresun University of Medical School, Department of Cardiology, Giresun, Turkey \\ ${ }^{4}$ Erzurum State Educating and Training Hospital, Department of Cardiovascular Surgery, Erzurum, Turkey \\ ${ }^{5}$ Akdeniz University of Medical School, Department of Cardiovascular Surgery, Antalya, Turkey \\ Our research was carried out in Akdeniz University of Medical School, Department of Cardiovascular Surgery, Antalya, Turkey
}

\begin{abstract}
Objective: The aim of this study was to assess the effectiveness and safety of autologous bone marrow stem cell (ABMMNC) treatment in patients with thromboangiitis obliterans (TAO, Buerger's disease).

Materials and methods: In this prospective study, twenty-two male patients with TAO were treated with ABMMNC implantation. All patients were Class II and III according to Rutherford Classification with a mean age of $48.27 \pm 11.55$ years. The mean follow up period was $30 \pm 22.12$ (range 9-64) months. Control visits were at weeks 4, 12 and 24. At each control visit, collateralization scores with digital substrat angiography (DSA) or computerised tomography (CT) angiography, treadmill maximum walking distance test, ankle brachial pressure index (ABPI) measurement and visual analogue scale (VAS) evaluation were performed.

Results: The treadmill painless walking distance test was found $272.27 \pm 164.96$ meter $(\mathrm{m})$ before implantation, and $310 \pm 172.54 \mathrm{~m}$, six months after the ABMMNC implantation $\left(p=0.003^{*}, p<0.008\right)$; the mean VAS scores before implantation, and after 6 months were $6.25 \pm 1.50$, and 5.01 \pm 0.86 . $\left(p=0.003^{*}, p<0.008\right)$. The mean ABPI (demonstrating the tissue perfusion) before and 6 months after implantation were $0.507 \pm 0.06$ and $0.66 \pm 0.1$ ( $\left.p=0.003^{*}, p<0.016\right)$. Six months after implantation, new collateral development was evaluated by angiography and collateralization scores were +3 in 8 patients, +2 in 4 patients, +1 in 8 patients and +0 in 2 patients.

Conclusion: The findings of this study suggest that ABMMNC implantation in the treatment of patients with TAO might be safe and effective option for treating ischaemic limbs.
\end{abstract}

\section{Introduction}

The TAO disease is an episodic, inflammatory, obliterativethrombotic, non-atherosclerotic, non-destructive disease with unknown etiology and clear segmentations. It generally leads to gangrene and tissue loss.

The only measure that may prevent progression of the disease is to stay away from smoking any kind of tobacco products. The efficacy of surgical sympathectomy in treatment has not been elucidated yet [1]. Revascularization cannot be performed in many patients due to distal involvement of vessels [2]. Medical treatment is not effective in reducing amputation rates, thus cellular treatment strategies in these patients may be useful for induction of therapeutic angiogenesis [3].

In 2002, Tateishi Yuyama and colleagues [4] demonstrated that ABMMNC implantation induced collateral development in patients with peripheral artery disease. The aim of this study was to investigate the efficacy and safety of ABMMNC implantation in patients with TAO.

\section{Materials and methods \\ Patients and study design}

The study included 22 patients who admitted to cardiovascular surgery department between May 2008 and June 2014. All of the participants were male subjects. The mean age was $48.27 \pm 11.55$ years. The mean height was $165 \pm 8.43 \mathrm{~cm}$, and the mean weight was 66.72 $\pm 8.68 \mathrm{~kg}$. All patients were Class II and III according to Rutherford Classification. None of the patients achieved revascularization by surgical or non-surgical approaches. The local research ethics committee approved the study.

The inclusion criteria were presence of single side leg ischemia and ischemia-related leg pain, no improvement or disease progression in clinical picture with stop smoking 6-months before ABMMNC implantation, no clinical improvement despite intravenous iloprost infusion, presence of vessel lesions that are not feasible for revascularization through surgical or non-surgical methods, presence of skin ulcerations following at least a 6-month regular wound care, class II or class III according to Rutherford classification, approval of

Correspondence to: Rasim Kutlu, Ass Professor, Giresun University of Medical School, Department of Cardiology, Giresun, Turkey, E-mail: dr.rasim@mail.ru

Key words: Ihromboanjiitis obliterans, stem cell, neovascularisation, treatment

Received: June 12, 2016; Accepted: July 05, 2016; Published: July 09, 2016 
volunteer participation through signing informed consent form.

The exclusion criteria were presence of atherosclerosis, diabetes mellitus or connective tissue disease, diseases that may lead to embolism such as atrial fibrillation, neoplasia or other co-morbidities; primary hematological disorders; proliferative retinopathy; entrapment syndrome, drugs abuse such as cocaine, amphetamine, cannabis or cigarette smoking; and osteomyelitis.

Routine laboratory tests and serological tests were performed for each patient at the time of admission to outpatient clinics. In addition, complete blood count, liver function tests, kidney function tests, fasting blood glucose, urinalysis, erythrocyte sedimentation rate, c-reactive protein (CRP), rheumatoid factor, antinuclear antibody, antiphospholipid antibody, topoisomerase 1 (Scl-70), complement measurement, fibrinogen measurement, serum homocysteine level measurement and hypercoagulability tests (Protein-C, Protein-S, Antithrombin-III, Factor-V Leiden, Prothrombin gene mutation analysis), chest x-ray, electrocardiography (EKG) and echocardiography tests were performed. Before implantation, all patients underwent a detailed evaluation by an experienced hematologist. Acetylsalicylic acid (ASA) and clopidogrel were stopped 5 to 7 days before implantation.

All patients underwent a standard vascular examination. This examination included ABPI measurement for perfusion assessment, VAS for pain assessment, and treadmill test until ischemic pains.

\section{Visual Analog Scale (VAS)-pain}

The VAS for Pain is a standard $100-\mathrm{mm}$ visual analog scale that was used to obtain patient's self-assessment of pain. A score of 0 indicates 'no Pain', while a score of 100 indicates 'worst possible Pain' [5].

\section{Ankle Brachial Index (ABI)}

A doppler-derived arterial segmental pressures on the ankle and brachium with a standard adult cuff was performed, and ankle systolic blood pressure against brachial systolic blood pressure (normal range $>1.0$ ) was indexed. An increase in ABI of more than 0.1 as an improvement [6].

Systemic antibiotic treatment was prescribed to patients with ischemic skin ulcer. Wound care and debridement were performed to all patients before ABMMNC implantation. In the preoperative period, patients underwent Digital Subtraction Angiography (DSA) or CT angiography to evaluate collateral vessel development after treatment.

\section{Maximum treadmill walking distance}

The patients' maximum pain-free walking distance on the treadmill was recorded (the speed was adjusted to $2 \mathrm{~km} / \mathrm{hr}$ and the slope to $12 \%$ ).

\section{Collateralization scores}

The collateralization scores were evaluated by using the classification developed by Rentrop et al. [7]: grade $0=$ no visible filling of any collateral channels; grade $1=$ filling of side branches of the infarct artery; grade 2 = partial filling by collateral vessels; and grade 3 $=$ complete filling by collateral vessels.

\section{Bone marrow collection and preparation}

Bone marrow aspiration was performed two hours before ABMMNC implantation under general anesthesia from both spina iliaca posterior superior, and targeted $500 \mathrm{ml}$ bone marrow material in total. For bone marrow aspiration, pre-heparinized syringes and 16-gauge needles were used. During aspiration of bone marrow material, various depth levels were used in order to provide the most convenient preparation. The aspiration was performed under sterile conditions. All patients were monitored for vital parameters during aspiration.

Aspirated bone marrow material was collected into a Baxter bone marrow collection set and sent to apheresis unit. The product was taken to apheresis by using Fresenius P1y set Fresenius com-tech (Fresenius SE \& Co. KGaA-Homburg-GERMANY) device and refined. CD- $34^{+}$cell count and mononuclear cell separation were performed. The program provides $99 \%$ purified stem cell volume. From the total harvest volume of $500 \mathrm{ml}$, a $100-\mathrm{mL}$ final volume of dense mononuclear stem cell preparation was obtained. Each $1 \mathrm{~mL}$ of the final $100 \mathrm{~mL}$ mononuclear stem cell preparation contains $1.6 \pm 0.9 \times 10^{9}$ mononuclear cells. Total number of CD $34^{+}$stem cells in the mononuclear cell preparation is 53 $\pm 36 \times 10^{6}$. Nevertheless, cytofluorometric analysis revealed that the bone marrow autologous stem cell preparation had $99 \%$ purity and contained CD $45+$ cells at a percentage of $97.5 \% \pm 2.2$. G-CSF was not used on the obtained stem cells before and after implantation.

\section{Implantation of ABMMNC}

After apheresis, ABMMNCs were injected to the patient at four different steps. Each injection step was in parallel to ischemic stimulus.

At the first step of implantation, ergometric stress test was performed for each patient until the occurrence of lower limb ischemic pain. Step 2 followed this step and the second ischemic stimulus was applied by bringing the pressure level of sphygmomanometer to 20 to $30 \mathrm{mmHg}$ higher than systemic blood pressure at supine position. Thus blood flow was stopped and the ischemic stimulus was applied for several minutes. Then, pressure of the device was lowered and blood flow to lower limb was re-established. Common femoral artery (CFA) was palpated and punctured under the inguinal ligament and $10 \mathrm{~mL}$ stem cell preparation was injected into CFA. After the second step, the third step was started immediately. At the third step after intra-arterial part of implantation, the leg was wrapped by a blood pressure cuff again and inflated to $20-30 \mathrm{mmHg}$ above the systolic blood pressure for several minutes. After ischemic condition of the leg, the air was released from the cuff and intramuscular injection was performed. By intramuscular injection, $90 \mathrm{~mL}$ autologous bone marrow mononuclear cell preparation was implanted into quadriceps femoris muscle and gastrocnemius muscle. Implantation was started from $4-5 \mathrm{~cm}$ proximal to the occluded arterial segment and extended to distal direction. These injections were applied 10 different regions of both quadriceps femoris and gastrocnemius muscles. At each injection site, the needle was inserted to a 3-4 cm depth and 4-5 mL autologous bone marrow mononuclear cell preparation was injected. For injection, 22 gauge needles were used.

Patients were discharged one day after implantation if their hemoglobin and hematocrit levels were normal. They were advised to continue their medications and control visits. Patients were followed in a range of 9 to 64 months, the mean follow up period being 30 \pm 22.12 months. Control visits were at weeks 4, 12 and 24. At each control visit, collateralization scores with DSA or CT angiography, treadmill maximum walking distance test, ABPI measurement and VAS evaluation were performed. During follow up period, none of the patients experienced adverse events.

\section{Statistical analysis}

All analyses were performed using SPSS for Windows (version 11.00; SPSS, Inc., Chicago, IL). All data are presented as mean \pm SD 
values. Continuous data were analyzed by the nonparametric Wilcoxon test. A post-hoc analysis (Bonferroni adjusted Wilcoxon test) was used to compare the patients before and after ABMMNC implantation .The $\alpha$ value of 0.008 was found by pairwise comparison of the patients before and after $A B M M N C$ implantation for pain-free walking time and $V A S$ parameters. A p value less than 0.008 was considered statistically significant (Wilcoxon Signed-Rank Test). The a value of 0.016 was found by pairwise comparison of the patients before and after ABMMNC implantation for ABPI Test, and a p value less than 0.016 was considered statistically significant (Wilcoxon Signed-Rank Test)

\section{Results}

The results were presented as figures.

According to the results of treadmill painless walking distance test 6 months after the ABMMNC implantation, the mean walking distance was $310 \pm 172.54 \mathrm{~m}$ and the difference from pre-implantation measurement was $272.27 \pm 164.96 \mathrm{~m}$ which was significant by Wilcoxon signed ranks test with a Bonferroni correction $\left(\mathrm{p}=0.003^{*}\right.$, $\mathrm{p}<0.008$ ) (Figure 1).

The mean visual analogue scale scores before implantation, and after 6 months were $6.25 \pm 1.50$, and $5.01 \pm 0.86$. There was a significant difference of $1.97 \pm 0.86$ points between pre-implantation and postimplantation (6th month) VAS scores (Wilcoxon signed ranks test with a Bonferroni correction $\left.\mathrm{p}=0.003^{*}, \mathrm{p}<0.008\right)$ (Figure 2).

The mean ABPI (demonstrating the tissue perfusion) before and 6 months after implantation were $0.507 \pm 0.06$ and $0.66 \pm 0.1$. The mean difference between pre- and post-implantation ABPI was $0.15 \pm 0.07$ and it was statistically significant (Wilcoxon signed ranks test with a

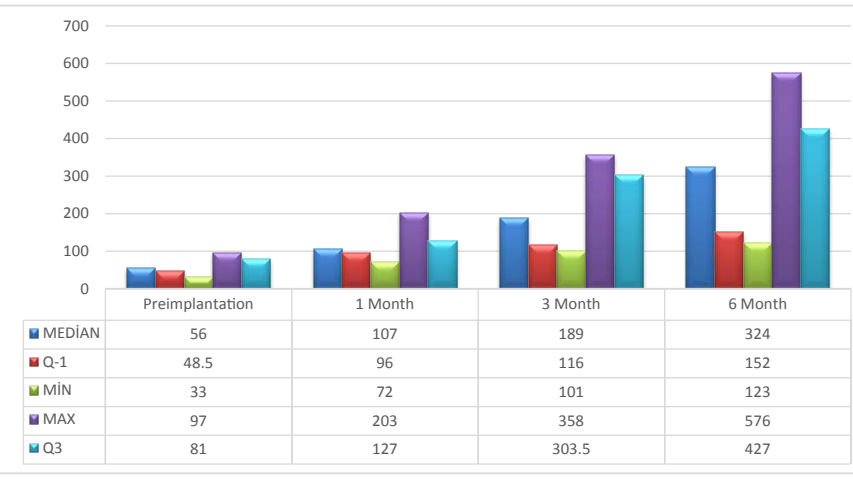

Figure 1. Painless walking time test at preimplantation visit and post-implantation months 1,3 and 6 control visits.

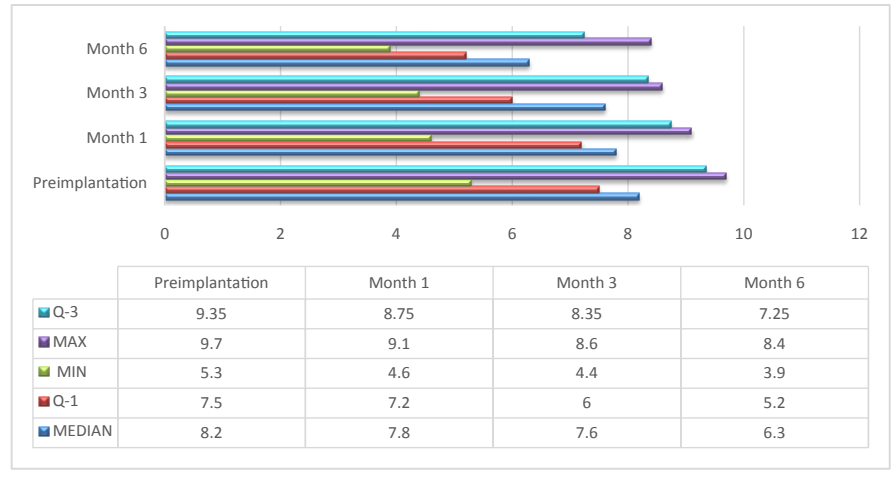

Figure 2. Visual Analogue Scale results at time points of pre-implantation, and postimplantation months 1,3 and 6 .

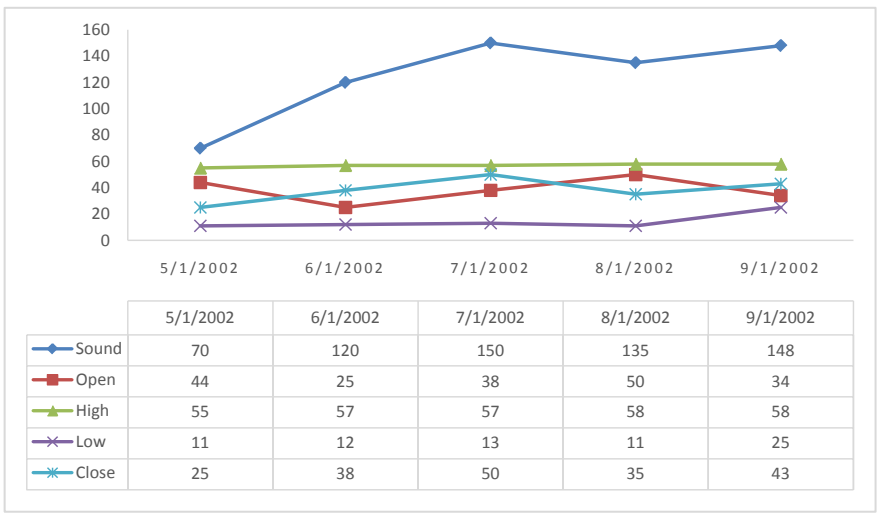

Figure 3. ABPI changes at time points of pre-implantation, and post-implantation 3 and 6 months.
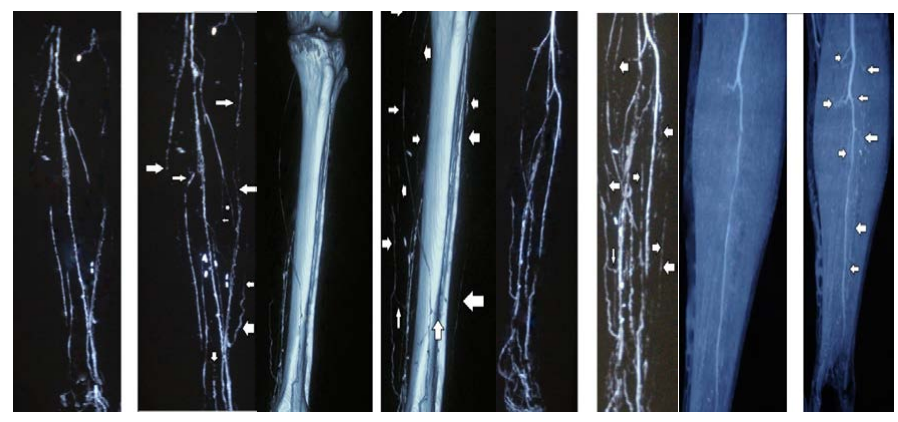

Figure 4. Pre- (left) and post-implantation (right) angiographic images of the patients Arrows show increased formation of collateral vessels compared to pre-implantation angiography (left).

Bonferroni correction $\mathrm{p}=0.003^{\star}, \mathrm{p}<0.016$ ) (Figure 3 ).

Six months after implantation, new collateral development was evaluated by angiography and collateralization scores were +3 in 8 patients, +2 in 4 patients, +1 in 8 patients and +0 in 2 patients (Figure 4 ).

\section{Discussion}

In this study, after ABMMNC implantation it was observed that better quality of life verified by increased painless walking distance, ABPI values, and collateralization in angiography and reduced visual analogue scale score, in patients with TAO and critical leg ischemia.

The safety and success of ABMMNC implantation were verified by animal model studies. Most of the animal studies used rabbits or rats. These studies demonstrated that impaired blood flow can be recovered and the blood supply to ischemic extremity can be reestablished by the above mentioned method. In the large amount of these studies, neovascularization occurred thanks to ischemic response of circulating endothelial progenitor cells $[8,9]$. These circulating cells are found in the capillaries and in arteries of ischemic tissue $[9,10]$. These cells can secrete cytokines and angiogenic growth factors via paracrine signalization and communication [11]. In the ex vivo studies on this therapeutic approach, human endothelial progenitor cells were transplanted to athymic mice with lower limb extremity and blood flow improved, collateral density increased and $60 \%$ extremity protection was provided. The extremity protection rate was only $7 \%$ in mice without endothelial progenitor cell transplantation.

Following TACT study [12], from various countries, the results of studies on the use of bone marrow stem cell preparations for ischemic conditions due to peripheral artery diseases were published $[13,14]$. 
While clinical human studies have been continuing, different cell types and isolation methods were used in animal models. Clinical studies to date have mostly used mixtures of mononuclear cells harvested from the bone marrow or peripheral blood. Furthermore, preclinical studies have identified several candidates, including adipose derived, embryonic and induced pluripotent stem cells [15]. In addition, these treatment methods were tested on different stages of various classification methods such as Rutherford and Fontaine.

Studies with bone marrow cell preparations used ABPI and $\mathrm{TcPO}_{2}$ measurements as perfusion parameters, and wound healing and walking distance as clinical outcomes. These parameters analyzed in different ways in studies with ABMMNC implantation. However, the biggest common point among these studies was positive improvement in all these parameters. When the data pool of autologous cell therapy studies are reviewed, positive improvements in these values can be seen. Accordingly, following an autologous bone marrow mononuclear cell implantation, ABPI values increase by 0.1 to 0.2 points, whereas transcutaneous oxygen pressure $\left(\mathrm{TcPO}_{2}\right)$ values increase by $10-20$ $\mathrm{mmHg}$. In addition, walking distance increases by 100 to 200 meters when compared to pre-implantation values.

One of the limitations of this study is relatively small numbers of patients consisting of male gender enrolled. Another potential limitation is the lack of some parameters for post-implantation term like $\mathrm{TcPO} 2$ of the lower extremity.

In most of the studies, cell therapy led to $\mathrm{ABPI}$ and $\mathrm{TcPO}_{2}$ increase together with visual analogue scale score decrease. However, large, randomized, placebo-controlled studies should be performed to increase the success rate of this treatment choice.

In conclusion, $\mathrm{ABMMNC}$ implantation in peripheral artery disease seems to be a promising treatment choice for patients with critical leg ischemia.

\section{References}

1. Roncon-Albuquerque R, Serrão P, Vale-Pereira R, Costa-Lima J, Roncon-Albuquerque R Jr. (2002) Plasma catecholamines in Buerger's disease: effects of cigarette smoking and surgical sympathectomy. Eur J Vasc Endovasc Surg 24: 338-343. [Crossref]

2. Durdu S, Akar AR, Arat M, Sancak T, Eren NT, et al. (2006) Autologous bone-marrow mononuclear cell implantation for patients with Rutherford grade II-III thromboangiitis obliterans. J Vasc Surg 44: 732-739.[Crossref]

3. Akar AR,Durdu S, Corapcioglu T, Ozyurda U (2006) Regenerative medicine for cardiovascular disorders.New milestones:adult stem cells. Artif Organs 30: 213-232. [Crossref]

4. Tateishi-Yuyama E, Matsubara H, Murohara T, Ikeda U, Shintani S,et al. (2002) Therapeutic angiogenesis for patients with limb ischaemia by autologous transplantation of bone-marrow cells: a pilot study and a randomised controlled trial. Lancet 360: 427435.[Crossref]

5. Burckhardt CS, Jones KD (2003) Adult measures of Pain: The McGill Pain Questionnaire (MPQ), Rheumatoid Arthritis Pain Scale (RAPS), ShortForm McGill Pain Questionnaire (SF-MPQ), Verbal Descriptive Scale (VDS), Visual Analog Scale (VAS), and West Haven-Yale Multidisciplinary Pain Inventory (WHYMPI). Arthrit Care Res 49: S96-S104.

6. [No authors listed] (1986) Suggested standards for reports dealing with lower extremity ischemia.Prepared by the Ad Hoc Committee on Reporting Standards, Society for Vascular Surgery/North American Chapter, International Society for Cardiovascular Surgery.J Vasc Surg 4: 80-94.[Crossref]

7. Rentrop KP, Cohen M, Blanke H, Phillips RA (1985) Changes in collateral channel filling immediately after controlled coronary artery occlusion by an angioplasty balloon in human subjects. J Am Coll Cardiol 5:587-592. [Crossref]

8. Shintani S, Murohara T, Ikeda H, Ueno T, Honma T, et al. (2001) Mobilization of endothelial progenitor cells in patients with acute myocardial infarction. Circulation 103: 2776-2779.[Crossref]

9. Takahashi T, Kalka C, Masuda H, Chen D, Silver M,et al. (1999) Ischemia- and cytokine-induced mobilization of bone marrow-derived endothelial progenitor cells for neovascularization. Nat Med 5: 434-438.[Crossref]

10. Asahara T, Masuda H, Takahashi T, Kalka C, Pastore C,et al. (1999) Bone marrow origin of endothelial progenitor cells responsible for postnatal vasculogenesis in physiological and pathological neovascularization. Circ Res 85: 221-228.[Crossref]

11. Kamihata H, Matsubara H, Nishiue T, Fujiyama S, Tsutsumi Y, et al. (2001) Implantation of bone marrow mononuclear cells into ischemic myocardium enhances collateral perfusion and regional function via side supply of angioblasts, angiogenic ligands, and cytokines. Circulation 104: 1046-1052.[Crossref]

12. Matoba S, Tatsumi T, Murohara T, Imaizumi T, Katsuda Y, et al. (2008) Long-term clinical outcome after intramuscular implantation of bone marrow mononuclear cells (Therapeutic Angiogenesis by Cell Transplantation [TACT] trial) in patients with chronic limb ischemia. Am Heart J 156: 1010-1018.[Crossref]

13. PeetersWeem SM, Teraa M, den Ruijter HM, de Borst GJ, Verhaar MC, et al. (2016) Quality of Life After Treatment with Autologous Bone Marrow Derived Cells in No Option Severe Limb Ischemia. Eur J Vasc Endovasc Surg 51: 83-89.[Crossref]

14. Franz RW, Shah KJ, Pin RH, Hankins T, Hartman JF, et al. (2015) Autologous bone marrow mononuclear cell implantation therapy is an effective limb salvage strategy for patients with severe peripheral arterial disease. J Vasc Surg 62: 673-680.[Crossref]

15. Furmston J, Patel AS, Ludwinski F, Zuzel V, Bajwa A, et al. (2014) Angiogenic cell therapy for critical limb ischemia: an update on concepts and trials. J Cardiovasc Surg (Torino) 55: 641-654.[Crossref]

Copyright: (C2016 Tekin AI. This is an open-access article distributed under the terms of the Creative Commons Attribution License, which permits unrestricted use, distribution, and reproduction in any medium, provided the original author and source are credited. 